\title{
PKM Katekese Tentang Menghayati Nilai Kekeluargaan dalam Era Digital bagi Para Orangtua Peserta Komuni Pertama
}

\author{
Aurelius Fredimento ${ }^{*}$, Gregorius Sebo Bito², Berty Sadipun³, John M. Balan4, \\ Nong Hoban 5 \\ 1,2,3,4,5 Universitas Flores, Ende, Indonesia \\ *Corresponding Author: betlehemk@gmail.com
}

\begin{abstract}
Info Artikel
Diterima : 03/01/2021

Direvisi: 29/01/2021

Disetujui: $21 / 02 / 2021$

Abstract. The communication media as a work of human beings reason from time to time has a very rapidly progress together with the growth and the development of new innovations in the world of the digital technology. This progress is a certainty that must be received by the human beings who are in a strong mind and conscience awareness that communication media is so sophisticated but remains as a means of the development of the human beings civilization. This awareness gradually can be expected to encourage human beings in order to place themselves appropriately as the subject of the development of the communication media itself through a rational and an accurate filtering process against negative influences that can threaten with human beings civilization. One of the institutions is threatened with the negative influences of the communicaton media is family. At first the family gets a respected position as a socialization agent about the values of life is now experiencing decline of function as well as its role because the majority of the family members are now snared because of the negative influences of the communication media. The sympathetic as well as the empathetic atmosphere are used to be the first decoration in the house and now is just becoming a nice memory but sadden. The fascination is too axtreme makes each of the family member of the communication media and finally appear some attitudes as well as behaviours that don,t go with the values of solidarity and the family as well. At last, this problem lets grow as well as develop without striving for preventive and curative of the various social elements. This meant preparing a show of a destruction of the generation in the future. Therefore, the whole sides are expected to their involvement to be a foremost line in preventing efforts. On the basis, the Paroki St. Yosef Onekore is also moved at giving the basics correct of comprehension to the parents in the catechetical activities that the communication media is actually just a means of using it to proclaim the King of God.
\end{abstract}

Keywords: Communication Media, Values of Solidarity, Church, Christian family

\begin{abstract}
Abstrak. Media komunikasi sebagai karya akal budi manusia, dari waktu ke waktu mengalami kemajuan yang sangat pesat seiring dengan bertumbuh dan berkembangnya inovasi-inovasi baru dalam dunia teknologi digital. Kemajuan ini merupakan sebuah keniscahyaan yang harus di terima oleh manusia dalam kesadaran akal budi dan nurani yang kuat bahwa media komunikasi meski dalam keadaan yang secanggih apapun, tetaplah merupakan sebuah sarana demi kemajuan peradaban manusia. Kesadaran ini, secara perlahan-lahan diharapkan dapat mendorong manusia untuk memosisikan dirinya secara tepat sebagai subyek perkembangan media komunikasi itu sendiri melalui proses filterisasi yang rational dan akurat terhadap pengaruh negatif yang bisa mengancam peradaban manusia. Salah satu lembaga yang terancam mendapat serangan dari pengaruh negatip media komunikasi adalah keluarga. Keluarga yang semula mendapat posisi terhormat sebagai agen sosialisasi pertama nilai-nilai kehidupan, kini mengalami kemerosotan fungsi dan perannya karena mayoritas anggota keluarga saat ini mulai terjebak dalam cengkeraman pengaruh negatip media komunikasi. Suasana simpatik dan empati yang dahulu menjadi hiasan utama dalam rumah, kini hanya menjadi sebuah kenangan indah masa lalu yang memilukan. Keterpesonaan yang terlampau ekstrim masing-masing anggota keluarga pada media komunikasi akhirnya melahirkan deretan sikap dan perilaku yang jauh dari nilai-nilai solidaritas dan kekeluargan. Membiarkan hal ini bertumbuh tanpa upaya prefentif dan kuratif dari pelbagai elemen masyarakat, berarti sedang mempersiapkan sebuah tontonan kehancuran generasi pada masa yang akan datang. Oleh karena itu, semua pihak diharapkan keterlibatannya menjadi garda terdepan dalam upaya pencegahannya. Atas dasar itu, Gereja Paroki Santo Yosef Onekore pun merasa tergerak hati untuk memberikan dasar-dasar pemahaman yang benar kepada orangtua dalam kegiatan katekese bahwa media komunikasi itu sesungguhnya hanyalah sarana yang dapat digunakan untuk mewatakan Kerajaan Allah.
\end{abstract}

Kata Kunci: Media Komunikasi, Nilai Kekeluargaan, Gereja, Keluarga Kristen

How to Cite: Fredimento, A., Bito, G.S., Sadipun, B., Balan, J.M., \& Hoban, N. (2021). PKM Katekese Tentang Menghayati Nilai Kekeluargaan dalam Era Digital bagi Para Orangtua Peserta Komuni Pertama. Prima Abdika : Jurnal Pengabdian Masyarakat, 1(1), 26-33. https://doi.org/10.37478/abdika.v1i1.944

Copyright (c) 2021 Aurelius Fredimento, Gregorius Sebo Bito, Berty Sadipun, John M. Balan, Nong Hoban. This work is licensed under a Creative Commons Attribution-ShareAlike 4.0 International License. 


\section{Pendahuluan}

Media komunikasi sebagai karya akal budi manusia dari waktu ke waktu mengalami kemajuan yang sangat pesat seiring dengan bertumbuh dan berkembangnya inovasi-inovasi baru dalam dunia teknologi digital. Pesatnya pertumbuhan dan perkembangan media komunikasi ini akhirnya mampu merobek sekat-sekat pemisah antara wilayah, suku, agama, ras dan budaya. Belahan-belahan dunia dengan aneka peristiwanya yang khas dan unik dalam sekejap saja sudah menjadi konsumsi global. Inilah sebuah kekaguman fantastis yang harus diterima dan diakui oleh manusia karena perkembangan dan kemajuan media komunikasi. Perkembangan dan kemajuan media komunikasi secara faktual membawa manusia pada sebuah titik ambiguitas yang melelahkan karena ditawarin 2 (dua) pengaruh yang harus disikapi secara rasional dalam kematangan pribadi yang utuh, yakni pengaruh yang positip dan pengaruh yang negatip (Fredimento \& Balan, 2020). Tegangan yang melelahkan ini pada titik tertentu dapat saja melahirkan manusia dengan 3 (tiga) tipe yang berbeda dalam merespons perkembangan media komunkasi, yakni: 1) manusia sebagai pribadi yang menolak perkembangan media komunikasi; 2) manusia sebagai pribadi yang menerima perkembangan media komunikasi namun dalam kontrol budi dan hati dan 3) manusia sebagai pribadi yang menerima perkembangan media komunikasi tanpa kontrol budi dan hati. Ketiga hal ini merupakan sebuah fakta riil yang pasti terjadi dan oleh karenanya harus diterima dan disikapi secara lebih bijak oleh banyak pihak.

Salah satu pihak yang peran dan tanggungjawabnya tidak boleh diabaikan dalam menyikapi hal ini adalah Gereja. Gereja dalam karya profetisnya, harus menunjukan keberpihakannya dalam menjelaskan, menuntun dan mengarahkan umat tentang apa dan bagaimana media komunikasi itu serta bagaimana seharusnya umat menggunakan media komunikasi itu sebagai sarana pengembangan dan peningkatan iman umat di tengah perkembangan dunia yang makin modern saat ini. Untuk mencapai harapan demikian, Gereja di tuntut untuk dapat membangun kerja sama yang intens dengan pelbagai pihak, supaya pemakaian media komunikasi ini sunguh-sungguh bertangungjawab demi tegaknya nilai-nilai Kerajaan Allah. Selain itu, Gereja dalam karya profetisnya juga di tuntut untuk menghidangkan secara transparan tentang efek negatip penyalahgunaan media komunikasi yang dapat menghancurkan dan membinasakan hidup manusia (Subu, 2014; Kristiyanto, 2010). Tangung jawab moral ini tumbuh dan berkembang dari sebuah kesadaran bahwa antara perkembangan media digital dengan konteks kehidupan sosial kemasyarakatan terdapat hubungan yang sangat erat satu terhadap yang lainnya. Menurut Liliweri bahwa antara teknologi dengan masyarakat memiliki titik keterhubungan simbiosis yang sangat signifikan. Artinya teknologi di satu sisi dapat mempengaruhi budaya manusia dan sebaliknya budaya manusia dapat mempengaruhi teknologi. Sementara, secara sosiologis, keterhubungan ini bisa dijelaskan bahwa teknologi yang merupakan salah satu aspek karya akal budi, turut juga mempengaruhi setiap aktivitas, tindakan, serta perilaku manusia. Teknologi informasi dan komunikasi mampu mengubah pola hubungan dan pola interaksi antar manusia pada umumnya dan keluarga kristiani pada khususnya (Setiawan, 2017; Kusuma, 2019) 
Terdorong oleh rasa tanggungjawab ini, Paroki Santo Yosef OnekoreKeuskupan Agung Ende merasa terpanggil untuk menggunakan momentum pekan-pekan Pendampingan Orangtua Anak Sambut Baru ini, sebagai kesempatan berharga untuk menginformasikan sekaligus menyadaran para orangtua bahwa media komunikasi yang perkembangannya semakin berkembang pesat ahir-akhir ini, senantiasa membawa serta dua (2) pengaruh yang signifikan bagi hidup banyak orang, yakni pengaruh yang positip dan pengaruh yang negatip. Dan saat ini dua pengaruh tersebut seolah-olah sedang berada dalam pertarungan yang dasyat dalam merebut simpatik manusia untuk mengikuti jalur penaruh mana yang akan dilaluinya sesuai dengan bisikan hati dan budi manusia. Oleh karena itu, ketajaman budi dan nurani setiap individu menjadi faktor penentu ke arah mana manusia menjatuhkan pilihan terhadap 2 (dua) tawaran dari pengaruh media komunikasi, yakni pengaruh positip atau pengaruh negatip.

Pengaruh positip dari media komunikasi yang dapat di kemukakan saat ini yakni sebagai sarana untuk menjalin keakraban dan relasi yang intens antara sesama anggota keluaraga dalam suasana kasih dan persaudaraan. Hadirnya media komunikasi dalam aspek ini, justeru mempertajam dan menguatkan jalinan relasi cinta antara anggota keluarga dalam keeratan dan keintiman kasih yang jujur dan melayani. Sedangkan pengaruh negatip media komunikasi bagi keluarga yakni terlahirnya aneka persoalan pelik yang mencemaskan keluarga. Kebersamaan dan keutuhan hidup perkawinan sering terganggu oleh kehadiran media komunikasi. Suasana keakraban penuh tawa dan canda ria antara sesama anggota keluarga menjadi sirna karena kesibukan masing-masing anggota keluarga dengan medianya sehinga melahirkan sikap egoisme yang dapat memandulkan aspek kepekaan hati dan toleransi terhadap orang lain yang berada di sekitarnya. Informasi yang anggota keluarga terima dari media digital sering kali menawarkan aneka sajian sensasional yang dapat mengancam keutuhan kehidupan keluarga, antara lain: egoisme, perselingkuhan, pornografi, kontrasepsi, aborsi, homoseksualitas dan lesbianitas (Sudi, 2018; Haryatmoko, 2007)

Mengatasi hal demikian, salah satu kegiatan yang terasa urgen untuk dilaksanakan pada pekan-pekan Pendampingan Orangtua Anak Sambut Baru Paroki Santo Yosef Onekore-Keuskupan Agung Ende adalah kegiatan katekese dengan tujuan untuk membuka cara pandang orangtua tentang bagaimana seharusnya menggunakan media komunikasi sebagai kerangka promosi bagi pematangan penghayatan nilai-nilai perkawinan dalam keluarga mereka sebagai komunitas cinta dan komunitas iman. Melalui kegiatan katekese ini, setiap orangtua anak sambut baru Paroki Santo Yosef Onekore-Keuskupan Agung Ende di sadarkan bahwa media komunikasi secanggih apapun, tetaplah menjadi sarana untuk suatu tujuan hidup perkawinan yang lebih luhur dan mulia yakni, unitif (menyatukan), partisipatif (mengambil bagian), edukatif (mendidik), transformatif (mengubah dan membaharui hidup). Untuk tercapainya cita-cita ini, perlu kerja sama yang intens antara keluarga dengan Gereja dan masyarakat dalam memberikan bimbingan dan tuntunan bagi pasangan suami dan isteri agar dapat hidup secara bijak sebagai keluarga beriman dalam era budaya digital. Akhir dari Kegiatan Katekese ini, orangtua anak sambut baru Paroki Santo Yosef Onekore-Keuskupan Agung Ende diharapkan agar mampu menjadikan diri mereka sebagai subyek media sosial 
dalam hal memberikan contoh dan teladan bagi sesama anggota keluarganya bahwa ekspresi cinta dan komunikasi yang langsung dan nyata justru menjadi obat terampuh dalam mempertahankan persekutuan cinta yang telah dibangun.

\section{Metode Pelaksanaan}

Langkah pertama yang dilakukan oleh tim pengabdian masyarakat ini adalah melakukan komunikasi dengan pihak Paroki Santo Yosef OnekoreKeuskupan Agung Ende dalam rangka sinkronisasi program kerja antara kedua lembaga ini sehingga tawaran tema yang diberikan sungguh menyentuh konteks riil dalam paroki. Proses sinkronisasi ini akhirnya membuahkan hasil dengan diberikannya kesempatan seluas-luasnya bagi tim pengabdian masyarakat (khususnya untuk dosen pengash mata kuliah Pendidikan Agama Katolik) untuk melakukan kegiatan pengabdian dengan syarat tema kegiatan harus sesuai dengan program kerja paroki. Berpijak pada persetujuan dari pihak paroki, tim pengabdian masyarakat pertama-tama melakukan observasi kepada kelompok sasar, yakni orangtua anak sambut baru Paroki Santo Yosef Onekore-Keuskupan Agung Ende. Sasaran observasi ini adalah untuk mengetahui sejauh mana peran media sosial terhadap perwujudan nilai-nilai kekeluargaan dalam hidup mereka. Langkah selanjutnya adalah memenuhi semua tuntutan administrasi surat menyurat demi terlaksananya kegiatan ini. Setelah mendapat restu dari pihak-pihak terkait berhubungan dengan kegiatan ini, tim pengabdian masyarakat melakukan beberapa persiapan, yakni pembagian tugas sesuai dengan fungsi dan perannya masing-masing. Semua proses persiapan itu dalam kontrol dan pengawasan dosen pengampuh mata kuliah Pendidikan Agama Katolik dalam kerja samanya dengan pimpinan Paroki Santo Yosef Onekore-Keuskupan Agung Ende. Kegiatan ini dilaksanakan pada tanggal 10 Desember 2020 dan pada tanggal 11 Desember 2020. Untuk menyukseskan kegiatan pengabdian masyarakat ini, pihak Paroki Santo Yosef Onekore-Keuskupan Agung Ende bersedia memfasilitasinya dengan menyiapkan semua sarana dan prasarana yang di perlukan.

Kegiatan dilaksanakan di aula Paroki Santo Yosef Onekore-Keuskupan Agung Ende sebanyak 85 pasangan orangtua dengan fasilitatornya adalah dosen pengampuh mata kuliah Pendidikan Agama Katolik. Dalam kegiatan tersebut, metode yang di gunakan adalah metode amos. Metode amos adalah metode kontekstual yang dalam pelaksanaannya menempatkan realitas hidup peserta sebagai titik star refleksi kemudian membiarkan Firman Allah menerangi realitas ini. Dalam metode ini, semua paangan orangtua di ajak untuk membaca dan memahami Firman Allah dengan bertolak dari situasi hidup konkret yang mereka alami sehari-hari. Situasi hidup konkret yang mereka alami, dianalisis dengan bantuan pisau analisis sosial dengan tujuan mendorong pasangan orangtua untuk sendiri menemukan akar terdalam dari persoalan mereka serta sebab musababnya dan membiarkan Firman Allah menerangi, memberikan ilham, memberikan daya dorong dan semangat juang untuk mencari jalan pemecahan mengatasi persoalan di maksud (Tisera, 2002; Habur, 2020) 
Berikut ini dijelaskan tahapan-tahapan pelaksanaan kegiatan ini berdasarkan metode amos, yakni: (1) melihat kenyataan hidup. Pada bagian ini pasangan orangtua di ajak melihat masalah sosial atau kasus nyata yang peserta alami atau dengar berkaitan dengan efek penggunaan media sosial bagi penghayatan nilai kekeluargaan di rumah. Untuk mempermudah pasangan orangtua dalam melihat situasi hidup, fasilitator menghidangkan sebuah ceritera dan membagikan gambar. Ceritera dan gambar ini di jadikan sebagai bahan dasar refleksi bagi pasangan orangtua untuk menemukan masalah riil tentang pengaruh negatip penggunaan media sosial bagi penghayatan nilai kekeluargaan. (2) menggali akar masalah. Berdasarkan hasil penemuan masalah riil tersebut, pasangan orangtua difasilitasi untuk menemukan apa yang menjadi akar persoalannya. Tahap selanjutnya setelah menemukan akar persoalan dari masalah riil yang terjadi, beberapa pasangan orangtua di berikan kesempatan untuk menceriterakan pengalaman pribadi berhubungan dengan pengaruh negatip dari penggunaan media komunikasi yang mereka alami khususnya d rumah masing-masing. (3) mendengarkan Firman Allah. Firman Allah dalam Kitab Suci yang dipilih akan dijadikan sebagai sumber inspirasi untuk menilai semua temuan yang pasangan orangtua dapatkan berkaitan dengan hal-hal negatip yang dialami dari pengunaan yan salah terhadap media sosial. Pasangan orangtua dibiarkan untuk bergumul dengan diri tentang hal itu sambil terus membuka diri terhadap peran Firman Allah sebagai cahaya dalam menilai dan menerangi persoalan itu sehingga bisa dicari jalan pemecahan atas problem yang di alami peserta; (4) menanggapi masalah dalam terang Firman Allah. Pada langkah ini pasangan orangtua di biarkan membangun Rencana Tindak Lanjut sebagai tanggapan atas kehendak Alah yang didengarnya. Rencana tindakan ini harus konkret, tegas tetapi dalam semangat kasih tanpa kekerasan. Kegiatan ini membutuhkan waktu 2 (dua) jam.

\section{Hasil dan Pembahasan}

Terhadap keseluruhan proses katekese yang dilaksanakan, beberapa pasangan orangtua ketika dimintai pesan dan kesan, menyatakan bahwa proses katekese dengan metode amos yang sudah mereka alami ini, sangat bagus dan menyenangkan. Hal ini lebih disebabkan karena dalam katekese ini, mereka diberikan kesempatan seluas-luasnya untuk menggumuli tema itu secara bebas berdaarkan inspirasi Kitab Suci yang sudah diberikan. Hasil pergumulan yang panjang para orangtua ini, tidak terpendam dalam nurani masing-masing orangtua, tetapi dibagikan kepada peserta yang lain dalam sharing iman dengan tujuan saling memberikan peneguhan dan kekuatan iman bagi pasangan orangtua yang lainnya bahwa media sosial itu sesungguhnya baik ketika orangtua mampu mengontrol dan mengarahkan penggunaannya bagi penanaman nilai-nilai kekeluargaan dalam rumahnya masing-masing. Dan soal dampak negatip yang sering dialami, mayorotas orangtua mengakui dengan jujur bahwa sesunguhnya hal itu merupakan akibat dari lemahnya kontrol orangtua bagi anak ketika sedang menggunakan media sosial. Kesan umum dari pasangan orangtua yang dijumpai selama kegiatan ini adalah pasangan orangtua secara perlahan-lahan mulai memahami bahwa media sosial memiliki dampak positip maupun negatip bagi pembangunan nilai-nilai kekeluargaan. Tingkat pengaruh dua kekuatan media sosial ini sangat ditentukan oleh sikap dan disposisi batin pasangan orangtua dalam menyikapi media komunikasi. Semua proses ini akhir mendapat 
penguatannya dalam sebuah proses internalisasi melalui meditasi singkat. Dalam meditasi bersama ini, banyak sekali dijumpai peserta yang dengan penuh spontan dan kesadaran meminta kesempatan untuk menyatakan niat pribadi untuk selalu menjadi aktor terdepan untuk mendidik dan mengawasi penggunaan media sosial dalam rumah sehingga pengunaan media itu bukannya memporakporandakan nilai-nilai kekeluargaan yang sudah dibangun melainkan semakin membangun dan mengokohkan nilai-nlai kekeluargaan yang sudah dibangun bersama.
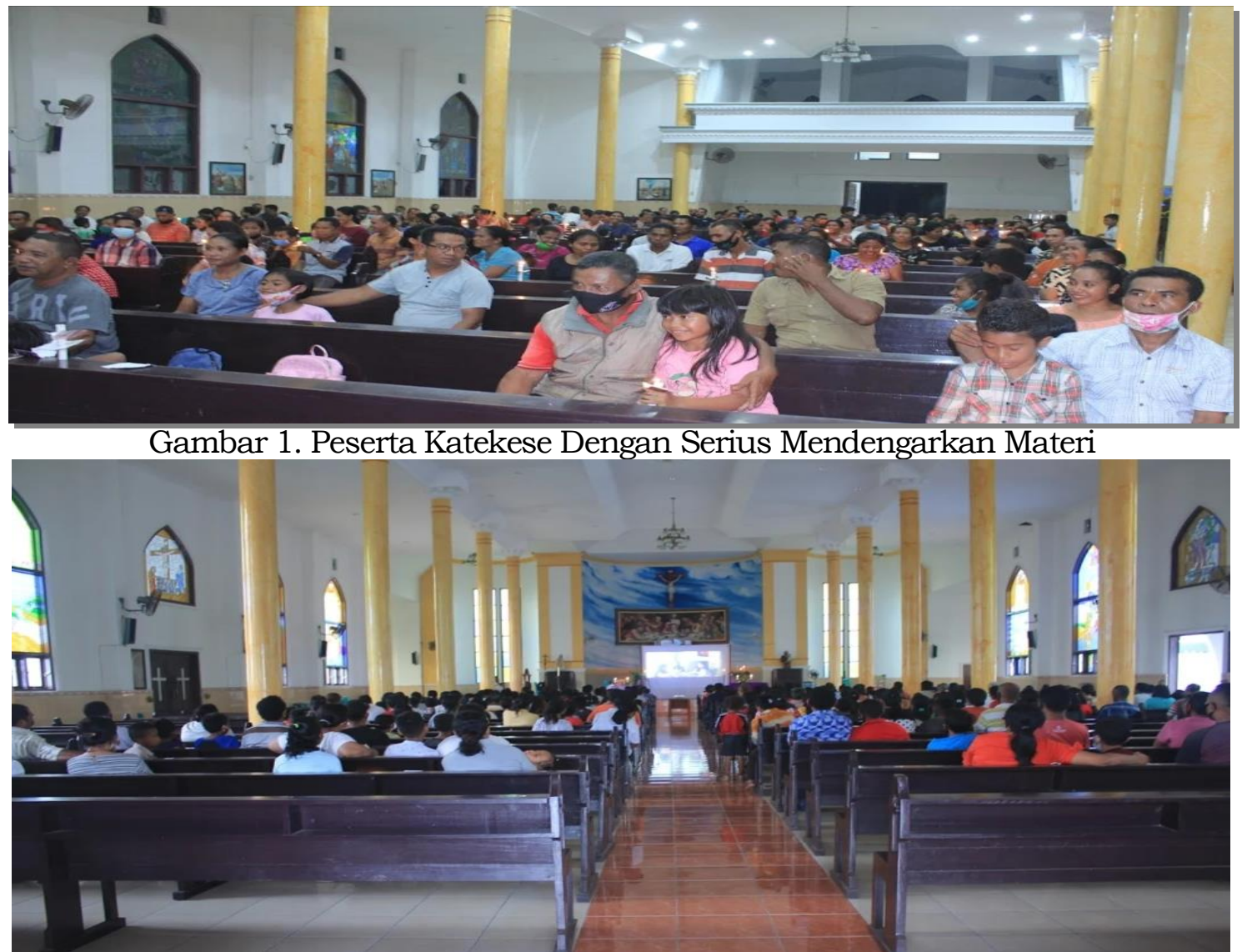

Gambar 2. Peserta Katekese Dengan Serius Menonton Video Edukasi

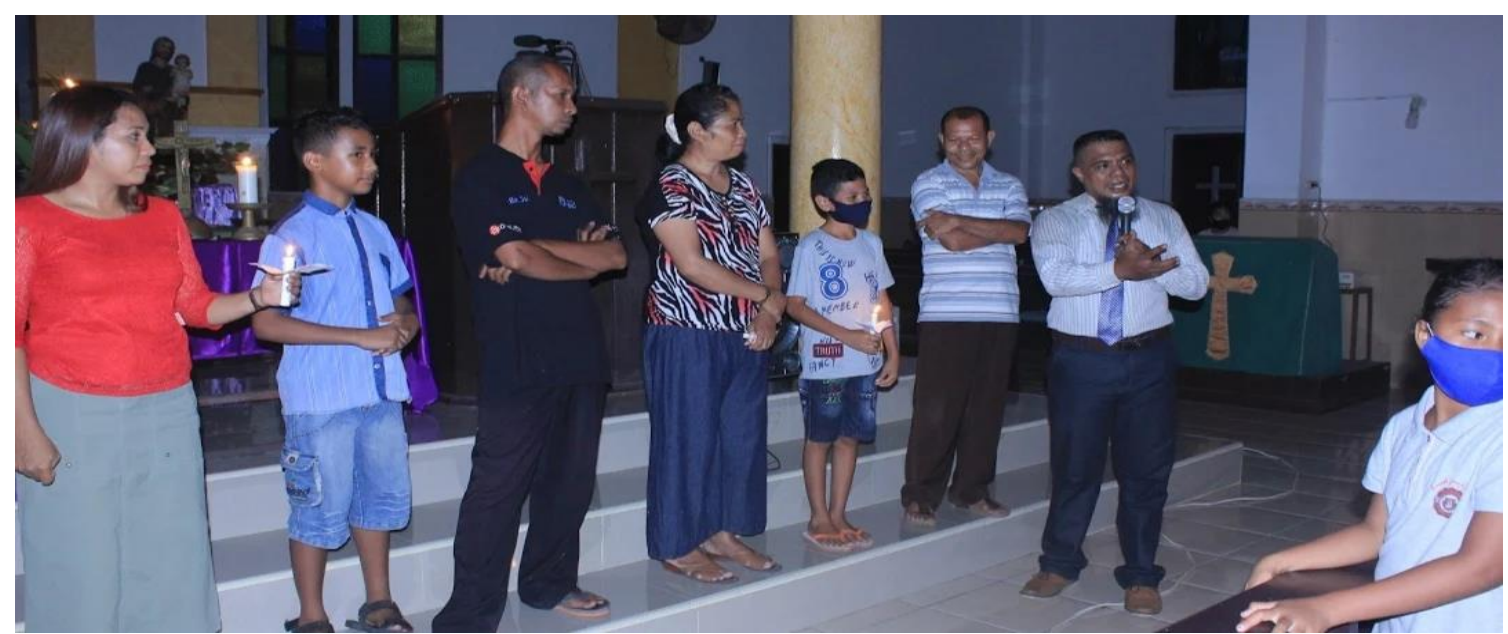

Gambar 3. Peserta Katekese Sedang Memberikan Sharing Pengalaman 


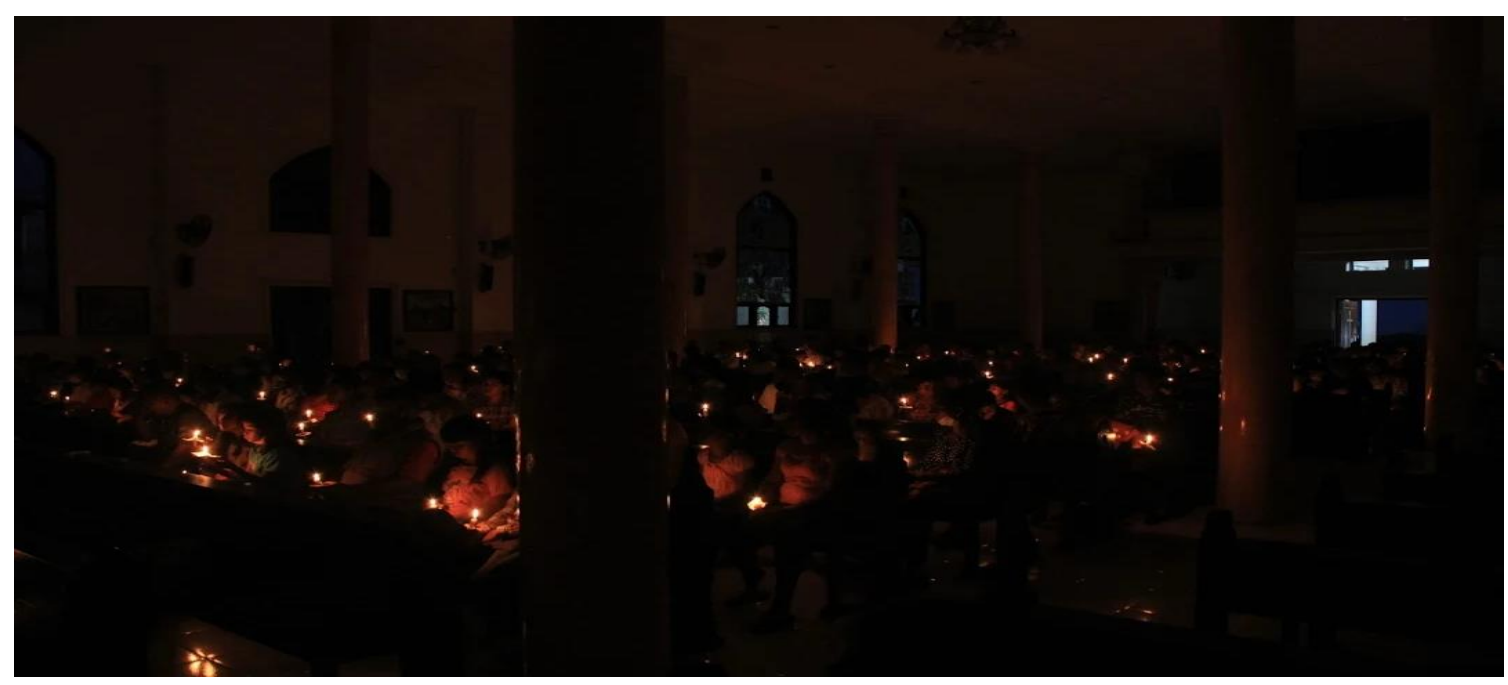

Gambar 4 Malam Internalisasi Dalam Meditasi Bersama

\section{Simpulan dan Tindak Lanjut}

Memperhatikan secara cermat kondisi riil pengaruh media komunikasi bagi penghayatan nilai-nilai kekeluargaan dalam rumah, dapat disimpulkan bahwa media komunikasi itu tidak bisa dipersalahkan sebagai penyebab utama merosotnya nilai-nilai kekeluargaan yang sudah wariskan, dihidupi dan diperjuangkan selama ini dalam keluaga. Hal ini disebakan karena media komunikasi itu sebenarnya merupakan sesuatu bukan seseorang. Sebagai sesuatu, media komunikasi itu harus diterima dan dimanfaatkan sebatas sarana atau media untuk perkembangan diri dan hidup manusia. Orangtua sebagai subyek dari media komunkasi, harus menampilkan diri sebagai pusat kontrol dan pusat kendali terhadap pengunaan media komunikasi oleh anggota keluarganya sehingga tidak menyimpang dari kaidah dan nilai-nlai kekeluargaan yang sudah dihidupi. Hal-hal seperti inilah yang justeru menjadi pusat pergumulan orangtua selama kegiatan katekese. Dalam kemasan metode amos, orangtua akhirnya dituntun untuk menemukan dan menyadari bahwa merosotnya nilai-nilai kekeluargaan sebagai akibat pengunaan yang salah dari media komunikasi, disebabkan oleh lemahnya kontrol dan kendali orangtua terhadap pengunaan media komunikasi dari anggota keluarganya. Akhir dari kegiatan katekese ini adalah terlahirnya sebuah kesadaran dan komitmen baru orangtua untuk selalu melakukan kontrol dan kendali terhadap pengunaan media komunikasi dalam rumah sehingga tidak membawa efek negatip bagi menurunnya penghayatan nilai-nilai kekeluargaan dalam rumah. Sedemikian penting dan mendesaknya kegiatan ini, maka orangtua menganjurkan agar pada masa yang akan datang, tema ini tetap dijadikan sebagai salah satu tema sentral dalam pendampingan bagi orangtua anak sambut baru demi pembaharuan dan peningkatan kesadaran orangtua tentang hakekat sebenarnya media komunikasi dalam membantu dan melayani manusia menuju aktualisasi diri yang sesunguhnya sebagai makhluk ciptaan Tuhan yang berharkat dan bermartabat. 


\section{Daftar Pustaka}

Habur, A. M. (2020). Diakonia Jantung Katekese. In Martin Chen \& Agustinus Manfred Habur (Eds.) Diakonia Gereja, 113. Jakarta: Obor

Haryatmoko. (2007). Etika Komunikasi, Manipulasi Media, Kekerasan, dan Pornografi. Yogyakarta: Kanisius.

Kristiyanto, E. (2010). Spiritualitas Sosial: Suatu Kajian Kontekstual. Yogyakarta: Kanisius.

Kusuma, R. A. (2019). Dampak Perkembangan Teknologi Informasi dan Komunikasi Terhadap Perilaku Intoleransi dan Antisosial di Indonesia. MAWA'IZH: Jurnal Dakwah Dan Pengembangan Sosial Kemanusiaan, 10(2), 273-290. https://doi.org/10.32923/maw.v10i2.932

Setiawan, D. (2018). Dampak Perkembangan Teknologi Informasi Dan Komunikasi Terhadap Budaya. JURNAL SIMBOLIKA: Research and Learning in Communication Study, 4 (1), 62-72.

Subu, Y. Y. (2014). Media Komunikasi Dalam Terang Dekrit Inter Mirifica. Jurnal Masalah Pastoral, 3 (1), 14-14.

Sudi, M. (2018). Implikası Perkembangan Teknolog1 Komunıkas1 Terhadap Peradaban Dan Komunikası Antar Manusia. Gema Kampus IISIP YAPIS Biak, 13 (2), 33-46.

Tisera, G., (2002). Shering Kitab Suci. Ledalero: Lembaga Pembentukan Berlanjut Arnold Jansen (LPBAJ).

Fredimento, A., \& Balan, J. M. (2020). PKM KATEKESE TENTANG MENGHAYATI NILAI KERAJAAN ALLAH DALAM ERA DIGITAL BAGI ANGGOTA KMK. ST. MARTINUS PAROKI PERSIAPAN ST. MARINUS PU'URERE. Mitra Mahajana: Jurnal Pengabdian Masyarakat, 1(1), 32-41. https://doi.org/10.37478/mahajana.v1i1.716 